\title{
К ВОПРОСУ ОБ ОПРЕДЕЛЕНИИ СОЗНАНИЯ. СОЗНАНИЕ КАК КАУЗАЛЬНОСТЬ БЕЗ ПЕРЕДАЧИ ИНФОРМАЦИИ
}

\section{ON THE QUESTION OF THE DEFINITION OF CONSCIOUSNESS. CONSCIOUSNESS AS CAUSATION WITHOUT INFORMATION TRANSFER}

\section{A. Safronov}

Summary: The article proposes a hypothesis that consciousness is a high-level interaction, which consists in the transmission of causality without the transmission of information. Some previously not discussed properties of consciousness are considered, including the property to occupy the position of a supersystem in relation to any system, including in relation to the states of consciousness itself, as well as the property to fill the Causal gap and the property to form a causal environment. The question of the correlation of neurophysiological approaches to the study of consciousness is considered in the example of the theory of integrated information by G. Tonini and the theory of cognitoma by K.V. Anokhin. It is concluded that Anokhin's theory has a much greater potential for development, however, this requires a new conceptual apparatus, as well as concepts of the causal environment, uncertainty and the concept of non-systems as complexes of non-interacting elements with each other.

Keywords: neural theories of consciousness, mental causation, information, theory of non-systems, causal environment.

\author{
Сафронов Алексей Владимирович \\ К.т.н., МГУ им. М.В. Ломоносова \\ alexey.safronov.w@gmail.com
}

Аннотация: В статье предлагается гипотеза, что сознание представляет собой высокоуровневое взаимодействие, которое заключается в передаче каузальности без передачи информации. Рассматриваются некоторые ранее не обсуждаемые свойства сознания, среди которых свойство занимать положение надсистемы, по отношению к любой системе, в том числе, по отношению к состояниям самого сознания, а также свойство заполнять каузальный разрыв и свойство формировать каузальную среду. Рассммотрен вопрос соотношения нейрофизиологических подходов к изучению сознания на примере теории интегрированной информации Дж. Тонини и теории когнитома К.В. Анохина. Делается вывод, что последняя теория имеет значительно больший потенциал для развития, однако, для это необходим новый понятийный аппарат, включающий такие понятия как каузальная среда, неопределенность, а также понятие 0 несистемах, как о комплексах невзаимодействующих друг с другом элементов.

Ключевые слова: нейронные теории сознания, ментальная каузальность, информация, теория несистем, каузальная среда.

\section{Свойство сознания передавать каузальность без переАачи информашии}

$\Pi$ очему герой романа Умберто Эко «Имя Розы» Вильгельм Баскервильский не стал смачивать слюной палец, листая экземпляр второй книги «Поэтики» Аристотеля? Потому что он догадался, что слепец Хорхе пропитал страницы этой книги быстродействующим смертельным ядом. Однако, что скрывается за формулировкой «он догадался»? Какого рода это влияние, и что выступает здесь в качестве причины? Если бы кто-то сообщил Вильгельму о том, что страницы пропитаны ядом, то причиной его предусмотрительного поведения было бы это сообщение. Но Вильгельму об этом никто не сообщал, и он сам сделал этот вывод, соотнося факты при расследовании преступлений в аббатстве. В то же время, сам Вильгельм никак не может быть единственной причиной собственного поведения в данном случае, так как ядовитые страницы книги являются для него внешним фактором. Так что же в мире романа Умберто Эко оказало это предупредительное влияние?

Мы вынуждены признать, что главная причина тако- го поведения Вильгельма, как ни странно, в том, что слепец Хорхе пропитал страницы ядом. Именно это в итоге остановило Вильгельма от опрометчивого поступка. Но эта же причина привела к иному результату в случае с несколькими жертвами Хорхе, которые не догадались о его коварстве. Различие между Вильгельмом и менее удачливыми временными обладателями книги Аристотеля в романе в том, что основная действующая причина (пропитывание листов ядом) действовала для них в разных условиях. И в случае Вильгельма эта причина действовала на него как недостающее звено в цепи рассуждений, как ключ к разгадке преступления, который позволил бы свести все части в единую картину. Хотя Вильгельм и получал сведения о смертях, и знал, что было орудие убийства, но он не знал какое это было орудие. Недостаток информации об этом побудил средневекового детектива смоделировать в своем сознании модель возможных вариантов прошлых и будущих событий. И его удачная догадка спасла его жизнь, одновременно погубив злодея.

Подобно Вильгельму Баскервильскому каждый человек прогнозирует в сознании прошлые и будущие события, достраивая, таким образом, неизвестную, но 
важную информацию о реальности или воображаемой реальности. В этом смысле каждый человек - немного детектив. Без такой способности человеку по-сути не было бы доступно очень многое, что мы считаем нормой в поведении. Как отмечает В.В. Васильев в книге «Сознание и вещи» [1], важным свойством сознания является его способность устанавливать принцип соответствия прошлого и будущего, и на этом основании в некоторой степени предвидеть какие-либо события будущего. Он пишет: «Вспомним, что принцип соответствия прошлого и будущего, из которого вытекает каузальная вера, говорит нам о том, что при полном повторении совокупных событий должны повторяться и те совокупные события, которые предшествовали им и следовали за ними в прошлом».

Вильгельм Баскервильский должен был знать о том, как ведут себя яды и наверняка сталкивался с их действием в прошлом, наблюдая жертв отравления. Однако, медицина описываемого времени не позволяла установить причину смерти, а улики, напротив, сбивали с толку. И все же Вильгельм догадался о яде. Как было отмечено выше, именно отравление листов книги Хорхе повлияло на поведение Вильгельма, в противном случае он не стал бы защищать свои пальцы от страниц отравленной книги. Но при этом, и это ключевой вопрос, имела ли место передача информации об этом событии к Вильгельму? Иными словами, было ли сопряжено это влияние с передачей информации? Как мы указали, о коварном деянии Хорхе никто в аббатстве ничего не знал. В то же время, нельзя сказать, что информации совсем не было. Но эта информация была как бы закодирована в происшествиях, мельчайших намеках, уликах, деталях, попавших во внимание Вильгельма. То есть можно условно сказать, что Хорхе послал Вильгельму и всем остальным «шифрованное» послание, но если другие в нем увидели предзнаменование и божий гнев, то Вильгельм смог его расшифровать.

Осознание чего-либо как моделирование прошлого или будущего, или их взаимосвязи, сопряжено с расшифровкой некоего кода, на что, в частности, указал Д.И. Дубровский, рассуждая о природе этого явления [2]. Он пишет, подразумевая под СР - субъективную реальность или просто сознание: «Рассмотрим пример. Я вижу сейчас дерево перед окном. Переживаемый мной образ дерева есть явление СР (обозначим его О), его носителем (согласно современным представлениям) является определенная мозговая нейродинамическая система (обозначим ее X). Связь О и X специфична в том плане, что $\mathrm{O}$ и $\mathrm{X}$ есть явления одновременные и однопричинные, они находятся в отношении взаимооднозначного соответствия. Такой тип функциональной связи я называю кодовой зависимостью. Х является кодом О. Поэтому нейро-физиологическое объяснение данного явления СР О состоит в расшифровке его нейродинамического кода X».
Там же он добавляет: «Что означает задача расшифровки кода? Ведь информация существует исключительно в кодовой форме. Это может означать лишь одно: преобразование непонятного для данной системы кода в понятный. А постольку существуют два типа кодов, я называю их «естественными» и «чуждыми». «Естественные» коды непосредственно «понятны» той системе, которой они адресованы, «прозрачны» для нее, не требуют операции декодирования (слово «дерево» сразу понятно человеку, хорошо знающему русский язык, ему не нужно специально (сознательно) анализировать физические и структурные свойства этого кодового объекта и т.п.). Информация в форме естественного кода «готова» для управления. «Чуждые» коды требуют декодирования. Но это означает не что иное, как преобразование «чуждого» кода в «естественный» код. После того как найден и закреплен способ такого преобразования, «чуждый» код становится для самоорганизующейся системы «естественным», что знаменует акт ее развития»».

Обратим внимание, что Дубровский не указывает на то, каким образом происходит расшифровка кода или «осознание» чего-либо. Он указывает, что есть процесс расшифровки, который переводит «чуждый» код в естественный. Но это не проливает свет на то, происходит ли эта расшифровка в тот момент, когда у человека оказывается вся необходимая информация или же он способен понять «чуждый» код и в ситуации недостатка или почти полного отсутствия информации. Заметим, однако, что в данном случае, это ключевой момент. Дубровский в том же исследовании пишет, что эволюционно кодовые зависимости и их расшифровка начинается со структур ДНК, и далее органически продолжается на уровне нейронных процессов. Так как для ДНК почти не применима успешная расшифровка неполных сообщений, можно предположить, что Дубровский имеет в виду под декодированием кода и под переходом от «чуждого» кода к «естественному» сбор недостающей информации, а не креативное формирование «догадки». Но ведь субъективная реальность воспринимается нами как творческая, креативная среда.

В связи с этим возникает непростой вопрос. Как соотносятся передача каузальности и передача информации для нейронных и ментальных процессов. Отражает ли человек реальность или хотя бы отчасти креативно формирует ее? Интуитивно нет сомнений, что он во-многом креативно формирует ее, поскольку имеет место воображение, предвидение, планирование и т.д. Человек формирует реальность ещё и потому, что она дана ему неполно, и известно, что имеет место лишь иллюзия полноты восприятия человеком окружающего мира. (Крис Фрит «Мозг и душа. Как нервная деятельность формирует наш внутренний мир»). Но это порождает парадокс. Если человек достраивает свою реальность, и при этом эта субъективная реальность соотносился с 
действительностью, значит, он успешно формирует эту реальность в условиях недостатка информации, причем далеко не всегда на основе опыта (или как его называет Васильев, принципом соотношения прошлого и будущего). И речь идёт не о кантовских синтетических суждениях априори, а о креативных «догадках» сознания, которые и отражают, и достраивают действительность.

Что есть такая догадка, или креативное озарение, или, проще говоря, что есть осознание, в таком случае? Чтобы приблизиться к ответу на этот вопрос, рассмотрим более подробно, отличие между ситуациями, когда передача каузальности и передача информации происходят вместе и когда каузальность не сопровождается передачей информации, необходимой в достаточной мере для каузального влияния. Очевидно, что в первом случае речь идёт об обычной каузальности, а во втором - о креативном озарении или догадке (хотя при этом догадка не обязательно должна быть верной). И главной проблемой здесь оказывается вопрос о достаточности информации для соответствия каузальному действию, и о возможности такого каузального действия при недостаточном уровне информации.

Является ли, например, передача закодированной информации достаточной для каузальности? Скажем, при соударении шаров каждый шар «сообщает» другому не только импульс, но и в полной мере информацию о своём импульсе. Так же и преподаватель, давая студентам домашнее задание, не только становится причиной того, что студенты будут его выполнять, но и делает это путем передачи информации. Каузальность в классическом случае происходит одновременно с передачей информации. Но если информация закодирована и не может быть раскодирована, то она как будто не оказывает и влияния. Так если преподаватель дает задание на китайском языке группе, не говорящей по-китайски, то задание вряд ли кто-то выполнит, и каузальность в привычном смысле как будто не будет иметь место. То есть условием классической каузальности является не просто передача информации, а передача информации в том виде, в котором она может быть декодирована. И в классическом случае здесь есть два варианта: либо адресат уже имеет ключ к коду, либо ключ содержится в самом послании. При этом большинство случаев, рассматриваемых в науке, относится к классической схеме связи информации и каузальности.

В физическом мире взаимодействие всегда подразумевает и передачу информации. Это относится и к классическому миру, и к релятивистскому, и к квантовому. Единственный процесс, для которого это правило, возможно, не выполняется это поглощение тела чёрной дырой. Есть предположения, что информация о поглощающем теле пропадает. Однако, нам в действительности неизвестно, что происходит при этом, и информация «стирается» для внешнего наблюдателя. Вполне можно предположить, что с точки зрения системы самого тела и чёрной дыры между ними происходит обмен информацией, как и в любом другом случае.

В мире химических соединений передача информации и каузальности также синхронизированы, но значительно усложняется набор взаимодействующих агентов, и повышается «ценз» взаимодействия. Чтобы вступить в химическую реакцию молекулы должны соответствовать набору взаимных условий. На биологическом уровне «ценз» ещё сильнее повышается. Взаимодействие молекул ДНК или, тем более, клеток, сопряжено с передачей информации между ними, но эта информация тщательно закодирована. И если декодирование информации не происходит, невозможно и взаимодействие. Сложность биологических кодов очень высока, и число возможных несовместимых другими с другом агентов взаимодействия резко возрастает.

Следующий принципиально более сложный уровень кодирования информации имеет место в нервной системе живых организмов. Это связано с тем, что нейронная система кодирования - коннектом мозга животного или человека - значительно сложнее, чем биологическая система кодирования - ДНК. Как пишет С. Сеунг [3]: «Ваш геном - последовательность нуклеотидов вашей ДНК, представляемая как длинный ряд букв четырехбуквенного алфавита. На рисунке показан фрагмент этой книги в три миллиарда знаков. Полный ее объем - миллион страниц. А коннектом - вся совокупность связей между нейронами нервной системы. Сам термин (как и геном) предполагает полноту охвата. Коннектом - не одна связь и даже не множество. Это все связи. Ваш мозг в принципе можно исчерпывающе описать такой же диаграммой, как и для червя C. elegans, только эта диаграмма будет куда сложнее».

Особенность кодирования для нервной системы заключается в том, что она имеет возможность кодировать не только внутренние состояния системы, но и создавать коды образов чувственный (внешних) объектов, и коды их взаимных соотношений. Кодируется также и ответная реакция агента, которая становится «зашифрованным» посланием для других агентов. Можно предположить, что при этом набор взаимодействующих агентов и набор шифров снова экспоненциально восторгает, и «ценз» взаимодействия, под которым мы понимаем сложность подбора «ключа» или декодирования одним агентом кода другого, также растёт. Поэтому обойтись без креативных «догадок» или озарений сознания на этом уровне, вероятно, уже невозможно. Креативность сознания становится вынужденной ценой за беспрецедентную сложность тех кодов, которые оно расшифровывает, по всей видимости, при недостатке информации. 
И остается вопрос: можно ли считать расшифровку сознанием таких кодов окружающего мира отражением, или необходим согласиться, что человек достраивает свою реальность сам? Учится ли человек, скажем, говорить на языке родителей, или творчески формирует свой язык в процессе общения с родителями? Изучаем ли мы в школе математику, или создаём свою математику, которая оказывается удивительно похожа на изучаемую... и так далее. Ведь если все это так, и верны эти гипотезы, то имеет место до сих пор неизученное явление природы - передача каузальности без передачи информации, которую мы привыкли называть творчеством.

Как было показано на примере выше, Вильгельм Баскервильский оказался единственным участником событий романа, кто смог полностью расшифровать действия слепца Хорхе. Настолько сложным и замысловатым был этот код. Вильгельм, как, впрочем, и настоятель аббатства, и ученик Вильгельма, и некоторые другие, осознавали, что имеет место «зашифрованное послание» ещё до того как оно было расшифровано. Или, переводя, на обычный язык, они осознавали, что имеет место некий набор неизвестных событий-причин, без которых невозможно объяснить происходящие события-следствия. Иными словами, действия Хорхе повлияли на окружающих людей при том, что никто ещё не знал какие и именно это действия.

Здесь может возникнуть сомнение, что причинами подозрений в аббатстве стали не действия Хорхе, а найденные там мертвые тела послушников. Ведь настоятель призвал Вильгельма к проведению расследования уже после того, как произошли убийства. Классические причины, как известно, всегда материальны, и нам кажется, что не может быть какой-то нематериальной причины. В частности, уже упомянутый выше В.В. Васильев [1, с.136] по этому поводу пишет: «Еще раз напомним, что каузальная вера требовала от нас признания того, что прошлые, уже несуществующие ряды событий могут влиять на актуальное развитие событий. Чтобы не впасть в противоречие, мы замещали эти несуществующие ряды событий актуальными ментальными состояниями. Но при такой замене получалось, что составные части причин наступающих событий не могут быть даны в нашем непосредственном опыте, что опять-таки не стыковалось с требованиями каузальной веры. Сейчас мы видим, как можно обойти эту трудность. Несуществующие ряды событий, влияющие на их актуальный ход, могут быть замещены не только приватными ментальными состояниями, но и некими физическими данностями, выражающими отличие того мира, в котором события будут развиваться одним способом, от того, в котором они развивались бы каким-то другим способом».

Действительно, мы всегда стремимся увидеть причины в физических данностях, и заменить в цепочке рассуж- дений все идеальные составляющие, на материальные. Но как в таком случае объяснить, что движущей силой для поведения человека становится его незнание? А точнее неполное знание. Настоятель аббатства догадывался, что имеет место цепочка намеренных убийств, но он не знал, кто убийца. Движущим мотивом чтобы призвать на помощь брата Вильгельма, таким образом, послужило частичное знание настоятеля аббатства, а точнее, незнание им всей картины. Формально под незнанием, мы, конечно, имеем в виду «знание о незнании», так как само по себе незнание не может приводить к активным действиям. Но что есть "знание о незнании», которое еще называют осознанием проблемной ситуации?

В терминах статьи, это зашифрованное послание, которое не содержит ключа для своего декодирования. О таком послании известно, что оно есть, но неизвестно, что оно означает. Например, как забытое слово, которое «вертится» на языке. В действительности, единственный способ расшифровать такое послание - метод перебора ключей или перебора «догадок». Сознание воссоздает смысл послания при разных воображаемых ключах и оценивает получаемый результат, и если оказывается, что какая-то из догадок даёт неожиданное совпадение, то такая догадка обретает статус озарения. Однако, примерно таков же механизм подбора ключей и между молекулами ДНК. Но есть и важное отличие, которое заключается в том, что, как мы указали, список для перебора возможностей для сознания непосильно велик. Чтобы совершать выбор в пользу одной из версий расшифровки послания в конечное обозримое время сознанию, вероятно, требуется не просто интуитивно сократить список перебора, щедро предлагаемого подсознанием, но и творчески, а значит с помощью образного или абстрактного мышления сконструировать свой вариант расшифровки.

На нейронном уровне этот процесс, вероятно, относится к наиболее сложным и энергозатратным. И он заключается в том, что в мозге формируются новые нейронные связи или в значительной мере и за очень короткое время (а не путём длительного обучения) изменяется сила существующих связей. Возможно, происходит какой-то дополнительный, до сих пор не изученный вид нейронной связи, сверхкоммуникация, нейронная сверхпроводимость или нейронный «пробой» (озарение), превышающий некое пороговое значение. Кроме того, в статье «Causal topology and non-material causes» [4] обсуждалась возможность динамических изменений на уровне каузальных топологий, резко повышающих эффективность возможных нейронных коммуникаций за счёт топологических эффектов в дополнительных измерениях. Все эти дополнительные возможности обсуждаются потому, что для решения такой задачи как производство обоснованной «догадки» нервной системе часто недостает проводимости каких-либо связей в 
существующей «нейросети», и она как бы достраивает недостающий для адекватного восприятия реальности уровень связей.

В то же время, представляется, что наиболее эффективной нейронной коммуникацией, которая позволяла бы решать человеку задачи такого уровня была бы неинформационная коммуникация. А именно коммуникация передающая каузальность без участия передачи необходимой информации. Необходимость таких коммуникацией обусловлена тем, что информационные коммуникации нейронов беспрецедентно сложны, и в рамках информационных потоков в мозге человека неизбежно должны формироваться области информационной неопределенности, области информационного разрыва, выделение в топологии нейродинамических процессов обособленных информационных онтологий. Также представляется, что сложность и уровень ментального восприятия действительности человека или животного непосредственно связаны со сложностью разветвленной системы таких обособленных областей, разрывов и неопределенностей, а не с уровнем интегрированный информации, как полагает, например, Дж. Тонини (теория интегрированной информации). Точно также как интеллектуальный уровень человека тем выше, чем в более сложных и неопределенных условиях он способен принимать адекватные решения.

При детальном изучении подобных ситуаций и случаев, когда сознание человека достраивает реальность и находит в ней незаполненные пустоты, и стремится их заполнить, как, например, в случае воображения, или когда мы говорим, что человек «догадался», «предвидел», «предвосхитил», следует предположить, что возможно имеет место каузальность без передачи информации. Как на нейронном, так и на логическом уровне.

По мнению таких исследователей как Д. Чалмерс [5] и Д.И. Дубовский [6], сознание как форма взаимодействия представляет собой информацию особого рода. Это не просто информация, а «информация об информации» или «информация изнутри». Действительно Вильгельм не имел информации о Хорхе, но он имел информацию о том, что информация о Хорхе существует. Он не знал, кто убийца и каково орудие убийства, но знал, что есть и то, и другое. Но как было показано, такая информация (об информации) далеко не всегда сама является информацией в том смысле, что она содержит в себе элементы неинформации, то есть того, что не может быть выражено «словами», пока оно не будет декодировано сознанием.

Также известны исследования Т.Нагеля [7] «Каково это быть летучей мышью?» и Ф.Джексон «Комната Мэри» [8], в которых допускается, что информация может быть также и нефизической. Нагель называет ее информацией «как», к Джексон приводит к понятию нефизической информа- ции в виде несуществующих на физическом (а значит и нейронном уровне) ощущений или восприятий, называемых квалиа. Оба исследования связывают сознание с нефизической информацией. К сожалению, эти исследователи не предложили нейронные модели сознания, которые бы связали квалиа с нейронными процессам.

Другой также уже упомянутый исследователь сознания Джулио Тонини [9] считает, что сознание является особой формой информации, а именно интегрированной информацией. По его мнению, информация возникает там, где уровень интегрированной информации очень высок. Также есть известная позиция Дж. Серля, который убеждён, что сознание связано с информацией, но при этом оно не сводится к известным нам информационным процессам в мозге. Иными словами, мозг, по его мнению, это не только компьютер, но и что-то ещё, и для объяснения сознания необходимо понять, что ещё делает мозг кроме передачи информации.

Отечественный исследователь сознания К.В. Анохин [10] также не сомневается, что сознание некоторым образом связано с информацией, но считает недостаточным исследование информационных процессов в коннектоме мозга, полагая, что сознание является продуктом надструктуры или гиперструктуры - когнитома мозга. По мнению Анохина, теория сознания должна учитывать тот факт, что сознание оперирует не просто безликими информационными связями, а смыслом.

Таким образом, практически все исследователи сознания сходится в том, что понятие сознания каким-то образом связано с понятием информация, и что это информация особого рода. Однако, до сих пор не было предложено исследовать этот вопрос с той точки зрения, что сознание есть передача влияния между агентами без передачи информации, либо с передачей закодированной информации, которую агент не в состоянии декодировать. В этом смысле сознание представляет способ существования каузальной связи между агентами в ситуации информационной неопределенности. Под агентами при этом понимаются как люди, так и каузально связанные нейродинамические области отдельного мозга.

Как указывалось выше, при переходе от физических к химическим и далее биологическим процессам резко возрастает «ценз» взаимодействия за счёт того, что усложняется, специфицируется передача информации. Возрастает демаркация «свой» - «чужой». Агентам становится все сложнее найти «своих». И поэтому естественно предположить, что на определённом уровне передача взаимодействия стала бы просто невозможна, если бы не возник дополнительный способ такой передачи - независимый от информационного потока.

О том, что сознание является эффектом сложности 
нейронной сети говорится уже давно, и этот путь исследования является до сих пор мейнстримом. Однако, мы видим, что многие прорывные работы в этом направлении, сделанные за последние десятилетия, так и не привели к пониманию природы сознания. Возможно, это связано с тем, что исследователи искали способы описания связей нейронов в сети, их комбинаций и т.п., но не учитывали то, что фундаментальная особенность сознания, вероятно, заключается не в интеграции информации, а напротив в ее «расщеплении», и что особенность «информации об информации» как раз заключается в том, что она может иметь место без самой информации, или без достаточного ее уровня.

Проведя теоретическое исследование свойств сознания и сопоставляя их с условиями нейронных процессов [11], автор статьи пришёл к выводу, что онтологическое или информационное «расщепление» необходимо для того, чтобы обусловить феноменальные свойства сознания, описанные Д. Чалмерсом, Т. Нагелем, Ф. Джексоным и др. Предельной возможностью, которую предлагает модель «нерасщепленного» нейронного процесса, является нейронная сверхпроводимость, или сверхэффективная нейронная коммуникация. В этом случае сознание представляется как нелокальная передача информации за счёт искривления каузальной топологии нейронных связей. Однако, даже такая теоретическая возможность недостаточна, так как не отвечает на вопрос «кто» является сознательным агентом (в формулировке К.В. Анохина). Онтологическое, или информационное, «расщепление» (что в силу Закона сохранения информации можно считать почти синонимами), напротив, позволяет теоретически выделять процессы относящиеся непосредственно к деятельности агента сознания, обусловить их взаимное отображение. В этом случае сознание также каузально «заполняет» информационный разрыв, описанный выше. Оно создает каузальную среду определенности в условиях недостатка информации.

\section{Свойство сознания формировать налсистему

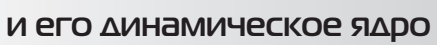

В пользу «расщепленной» или, проще говоря, не монистической концепции сознания косвенно говорят и другие его свойства. Например, это свойство - занимать положение надсистемы по отношению к бессознательным состояниям и сознательным состояниям более низкого уровня. Поясним это на двух примерах.

Первый пример имеет отношение к эволюции мозга. Известно, что мозг от животного к человеку эволюционировал путём усложнения структуры за счёт трансформаций и появления новых областей. Мозг имеет слоистую структуру. В частности, до сих пор есть животные, у которых основная часть мозга это ствол и мозжечок это рептилии. И посольскому можно предположить, что субъективный опыт таких животных формируется с помощью существующих отделов мозга, то мозжечок играет в этом важную роль. Дальнейшее развитие мозга связано, в том числе, с появлением коры полушарий. Вначале возникает древнейшая кора, потом старая кора, и потом новая кора полушарий головного мозга. Вероятно, что при таком развитии мозга субъективный опыт примата или человека формировался преимущественно за счёт все более новых структур. При этом более старые структуры приобретали смешанный функционал: мозжечок человека теперь во многом отвечает за координацию движений, области, связанные с древней корой - за обоняние, а старая кора преобразовались, например, в гиппокамп, где формируются эмоции и происходит консолидация памяти.

Можно предположить, что если в мозге человека именно новая кора отвечает за высшие нервные функции - сенсорное восприятие, выполнение моторных команд, осознанное мышление, речь у людей, то эта новая кора в то же время «лидирует», «задаёт тон» всему процессу субъективного восприятия, формируя как бы надсистему по отношению к предыдущим когнитивных «лидерам» в мозге. Однако, здесь весьма важно не следовать ошибочному суждению Пола Маклина [12], который предложил гипотезу о «триедином мозге», который состоит из трёх отделений - рептильный мозг, лимбическая система и неокортекс. По мнению Маклина, существует три центра психической активности, которые по-своему реагируют на происходящие события. Эта теория была опровергнута именно на том основании, что она разделяла мозг на самостоятельные области, что не подтвердилось на практике, так как несмотря на слоистую структуру мозг функционирует как единое целое. Поэтому предполагая, что более «молодые» отделы мозга «лидируют» в формировании ментальных процессов, мы в то же время имеем в виду, что они являются частью надсистемы, а не независимыми областями.

Принимая это ограничение, можно по аналогии распространить принцип материальной экспансии мозга на экспансию самого субъективного восприятия. В этом смысле, логично предположить, что «новое сознание» (в системе с участием новой коры) становится надсистемой по отношению к «старому сознанию» (в системе с участием «старой коры»), которое, в свою очередь, сформировало надсистему по отношению к «древнему сознанию» и также далее, по отношению к «мозжечковому сознанию» и т.д.

Как пишет выдающийся советский изобретатель и писатель-фантаст Г.С. Альтшуллер [13]: «Исчерпав возможности развития, система включается в надсистему в качестве одной из частей; при этом дальнейшее развитие идет на уровне надсистемы». И хотя советский учёный писал не о мозге, но аналогия явно прослеживается. Но- 
вые области мозга формируют «авангард» новой надсистемы, и соответствующая этим новым областям «новая ментальность» человека также образует надсистему в отношении предыдущего уровня ментальности.

Это свойство можно заметить не только при изучении эволюции мозга, но подобный механизм, такое свойство работы сознания проявляется, по всей видимости, ежечасно. Например, просыпаясь после сна, наполненного сновидениями, человек переключается от измененного состояния сознания к обычному состоянию сознания при бодрствовании. При этом на очень короткое время сознание бодрствования оказывается в положении надсистемы по отношению к измененному состоянию сознания сна, так как отдельные элементы содержания сна становятся доступны сознанию бодрствующего человека. Также важно, что это «сонное» сознание и его содержание, каким бы ярким оно ни было, со стороны надсистемы уже воспринимается человеком как, в какой-то мере, «чужое», «не настоящее». То есть ядро субъективного восприятия и ментальное «лидерство» перемещается на уровень надсистемы.

В теории Д. Деннета этот эффект называется «церебральное селебрити» [14]. Философ указывает, что одновременно мозг формирует множество ментальных проекций, каждая из которых имеет структуру сознания, но фактически сознательной становится в каждый момент времени только одна из них, захватившая общее внимание и влияние, - некая «церебральная» знаменитость. Однако, в течении дня происходит постоянный переход между этими проекциями, и «знаменитость» сменяется. «Сознание есть церебральная селебрити - не больше и не меньше. Осознаны те процессы, которые сохраняют и монополизируют ресурсы достаточно долго для оказания типичных и „симптоматичных“ воздействий на память, контроль за поведением и т. д.»

Однако, Деннет не говорит о том, что проекции, который в данный момент не являются «знаменитыми» входят в общую надсистему, а это крайне важно, постольку иначе упускается тот факт, что надсистема оказывается в отношении к предыдущей системе, и может формировать оценки по отношению к ней.

Например, когда человек говорит: «Неужели это сделал я», «Я был сам не свой», «Я был очень рассеян в этот момент и не мог сконцентрировать», это означает, что в момент говорения его текущее сознание составляет надсистему по отношению к состоянию сознания, о котором идёт речь. Более отчетливо и выпукло этот эффект можно наблюдать на уровне интроспекции бытовых ситуаций в течении дня. Например, автор статьи часто водит машину, и время от времени «ловит себя на мысли», что композиция, которая исполняется по радио ему не нравится. Но это часто происходит не сразу, и может быть даже в середине композиции, поэтому действие (переключение канала радио) следует не сразу, а только тогда, когда сознание, как утверждает Н. Блок, получило доступ к оценке ситуации.

В книге «Сознающий ум» [5] Д. Чалмерс подробно обсуждает подобные примеры, и в том числе пример из самого Н. Блока, тоже связанный с восприятием назойливого звука: «Что же касается существования феноменального сознания без сознания доступа, то здесь Блок упоминает несколько реальных случаев. Один из них это ситуация, в которой субъект неожиданно осознает тот факт, что уже какое-то время фоном в его ушах громко визжала дрель».

Оценка самого себя в прошлом как «рассеянного», «отвлеченного другими делами» подразумевает, что человек ставит себя в оппозицию к прошлому состоянию сознания. Поэтому «сознание доступа» к действиям по Блоку это тот же эффект «надсистемы», о котором идёт речь.

Такое любопытное свойство сознание - всегда быть центром лидирующей надсистемы - можно для наглядности представить в виде следующей метафоры «мозгового штаба». Представим, что происходит ограбление банка и есть заложники. На место быстрее всех прибывает местный полицейский и паркуется у входа в банк, обходит свой автомобиль и занимает положение в засаде. Все, что он может сделать как «мозговой центр» операции - это сообщить по громкоговорителю, что банк окружён, и вызывает подкрепление. На помощь полицейскому скоро приезжает шериф и его команда. «Мозговой центр» сбора информации и принятия решений переходит сразу же к шерифу, а полицейский выполняет его поручения. Допустим, что шериф узнаёт, что ограбление банка производится бандой, которая находится в федеральном розыске. Он сообщает это федералам, и те скоро выдвигаются на место ограбления. Теперь «мозговой центр» у них, но и шериф, и самый первый полицейский должны им помогать, входя в общую команду, как бы федералы не оценивали их первоначальные действия. И так далее, динамическое ядро «мозгового центра» перемещается в более значимую или энергетически ресурсную область.

Несмотря на то, что динамический центр или ядро сознания подвижно, сознание при этом имеет периферийные области всегда готовые занять центр динамического ядра. Надсистема сознания для его периферийных областей представляет собой среду, формирующую онтологическую возможность ментальных процессов вообще. Поэтому вопрос о сознании это, в том числе, и вопрос о соотношении свойств надсистемы и свойств среды, и вопрос об онтологическом статусе сред вообще. И это очень существенно, поскольку свойство сознания, рассмотренное в первой части статьи, также 
связано с этим вопросом. Что есть среда, формирующая ментальные проекции? Какой онтологический статус имеют информационные процессы и неинформационные процессы передачи каузальности, рассмотренные выше? За счёт чего формируется информационная неопределённость и «разрыв» в такой среде? И наконец, «кто» является агентом субъективного опыта? Все эти вопросы, в конечном счёте, это вопросы об онтологическом статусе среды.

\section{Сознание как среда}

В связи с перечисленными вопросами обратимся к передовым отечественным исследованиям в области сознания. Одно из важных исследований такого рода проводится группой ученых под руководством К.В. Анохина [10]. Как отмечает Анохин, ни одна из существующих научных нейронных теорий сознания сегодня не учитывает ответ на вопрос «кто» совершает те или иные действия. Мы бы дополнили этот вопрос, и спросили также, какие именно нейронные процессы в мозге необходимо считать производимыми автоматически (то есть бессознательно), а какие происходят в связи с творческой активностью субъекта, агента поведения, а не действием внешнего для него мира. Это вопрос отличается от вопроса о нейронных коррелятах сознания, который был поставлен Кригом и Кохом [15], так как подразумевает не просто корреляцию процессов с осознанностью действий, но и их корреляцию с субъектом. По сути, вопрос Анохина «кто», это проблема нейронных коррелятов субъекта или агента, а не просто коррелятов сознания.

В ответ на такую постановку проблемы, российский нейроученый предлагает подход, который в отличие от сугубо математического построения сети-графа нейронных связей мозга - создания так называемого коннектома - предлагает учитывать смысл нейронных процессов, их связь с внешним миром. Анохин называет такое построение - гипер-сетью, которая является мета уровнем для сети, и называет ее когнитом.

Идея К.В. Анохина и его последователей учитывает тот факт, что проблема нейронных коррелятов сознания до сих пор не привела исследователей к успеху. Действительно, прямая систематизация нейронных взаимодействий мозговой сети, попытка построения схемы работы мозга по принципу аппарата, состоящего из деталей, до сих пор не даёт результата. Почему? Вероятно, это связано с тем, что сеть первого уровня не учитывает роль агента в деятельности мозга, и этот уровень как бы не видит «лес» субъекта за «деревьями» нейронных процессов. Он не чувствителен к субъекту. В то же время, когнитом изначально рассматривается как взаимодействие «смысловых», а не «географических» областей мозга, что особенно актуально, учитывая, что человеческий мозг обладает большой пластичностью.
Области мозга могут адаптироваться к выполнению разных нейронных задач в случае травм, функционально заменять травмированные области и т.д. Кроме того, Анохин отмечает, что, описывая коннектом человека, мы не сможем распространить наше знание о работе этой сети на животных, так как у них подчас совершенно иное строение. Например, у птиц, при том, что птицы проявляют сознательное поведение.

Все это приводит к выводу, что сам по себе метод нейронных коррелятов сознания малопродуктивен. Речь должна идти не о тех или иных областях конкретного мозга, а о некоторых принципах, паттернах или отображениях нейронных активностей, которые могут проявляться в самых различных областях мозга. Как следствие должен быть подвергнут сомнению сам метод, при котором мозг воспринимается как «аппарат, состоящий из элементов, и производящий сознание». А это значит, что должна быть подвергнута сомнению и методика восприятия мозга как системы вообще и переход к пониманию мозга как среды (в том числе и как "несистемы” для дуалистических и плюралистических моделей).

В чем, однако, заключается отличие между системой (и аппаратом как воплощением системы) и средой? Например, колебательный контур является системой, в которой формируется электромагнитная волна. Эта система состоит из элементов - катушки индуктивности, емкости и проводников. Нам известно, что в такой системе возникает электромагнитная волна, но можем ли мы сказать, что колебательный контур представляет собой среду для электромагнитных волн. Вероятно, нет. Если представить себе гипотетическую ситуацию, что мы поместим колебательный контур в среду, где невозможны электромагнитные волны, то станет понятно, что средой для этих волн является вовсе не контур.

В отличие от аппарата, который локализует и функционально использует некоторый феномен, в среде этот феномен не локализован, и проявляется повсеместно в некоторых случайных эпицентрах или областях. Так, например, в определённой химической среде могут возникать те или иные химические соединения, но часто место их образования можно считать статистически случайным. Также в научной среде возможно появление научных открытий. Однако, процесс их возникновения не локален. Нельзя представить себе систему научного исследования как «аппарат, который штампует» научные открытия. Так как непонятно, кто и когда совершит открытие. Но могут создаваться такие условия, в которых научная среда, как целое образование, порождает научные открытия. Возможно, что мозг также является для сознания не аппаратом, а средой.

Стремление моделировать мозг как аппарат вполне понятно. Во-первых, очень многое из того, что человек 
до сих пор создавал, копируя природу, было в той или иной степени аппаратом, совокупностью элементов с разными функциями, работающих вместе. И если это справедливо для органов тела - конечностей, органов чувств, внутренних органов, почему бы это не было справедливо также и для мозга. Во-вторых, кроме того, отделы мозга часто имеют выраженную специализацию, и несмотря на пластичность, могут устойчиво отвечать за какие-либо функции, например за зрение, слух, абстрактное мышление, координацию движения или речь. Выявлено, что и отдельные группы нейронов или даже отдельные нейроны также могут специализироваться на конкретных задачах.

Поэтому мотивация разделить мозг как аппарат на «шестеренки», каждая со своими функциями, выглядит вполне оправдано. Особенно, когда речь идёт о зрении, речи, памяти или координации движения и т.п. Можно проследить за нервным импульсом, который передаётся от зрительных рецепторов через нервную систему в зрительную кору мозга, где он попадает в те или иные функциональные зоны этой коры, в зависимости от обстоятельств. Иными словами, мозг также часто ведёт себя как аппарат. Однако, перечисленные способности человека являются функциональными и отличаются от сознания по своей природе. Поэтому ответ на вопрос о том, является ли мозг аппаратом, взаимодействие частей которого порождает сознание, совсем не так очевиден.

Возможно, для сознания мозг представят собой часть фундаментальной среды его возникновения, а не систему «шестеренок», работающих в среде, в которой сознание уже обусловлено. В этой связи отметим, что К.В. Анохин подчеркивает, что сознание имеет биологическую природу, и возникает как высокоуровневый феномен именно в этом онтологическом слое, а например, не в физическом слое на уровне квантовых процессов. В то же время, понимание нервной системы как высокоуровневой среды снимало бы ряд вопросов, в частности, почему до сих пор не удается локализовать сознание в тех или иных областях мозга, в тех или иных нейронных комплексах. Но в ответ на это возникли бы другие вопросы.

Если мозг не аппарат, а фундаментальная среда, или часть среды, в которой сознание берет начало, то какая это среда? В чем ее специфика? Почему эта среда формирует субъективный опыт? Представляется, что гипер-сетевой подход формирования когнитома, разрабатываемый К.В. Анохиным, является более отвечающим на эти вопросы, чем сетевой подход коннектома, разрабатываемый сегодня англоязычными нейробиологами. Это связано с тем, что гиперсеть - когнитом рассматривает нейронные процессы как среду, где формируются более высокоуровневые гиперсетевые мета процессы, открывая более широкие теоретические и практические возможности.
Однако, гиперсетевой подход в той стадии разработки, в котором он существует сегодня, не снимает всех вопросов, и проблема природы субъективного опыта остаётся. Переход от сетевого к гиперсетевому уровню намечает решение проблемы обособления субъекта как уникального свойства, так как выделяет его из сугубо биологического уровня на более высокий. Однако, представляется, что для решения так называемой проблемы "душа-тело" необходимо, чтобы модель не просто обособляла субъекта, а включала в себя «онтологический разрыв». В противном случае граница субъекта оказывается размытой, а онтологический статус «кто», о котором пишет К.В. Анохин, остаётся по прежнему неопределённым.

В этой связи представляется, что гиперсетевая модель нервной системы человека могла бы учитывать более радикальные параметры, позволяющие моделировать «онтологический разрыв», описывая таким образом возникновение каузального и ментального агента на гиперсетевом уровне как «несистемное явление». Однако, такое более радикальное нововведение граничит с необходимостью учета возможностей, которые предполагают дуалистические теории сознания, или теория несистем, а именно двух- и мультисубстанциональность ментальных явлений. В частности, ранее об общих понятиях такие фундаментальных гипотетически возможных явлениях, как каузальная или онтологическая неопределенность и мультисусбанциональность, было упомянуто в [11].

Представляется, что феномен сознания может быть всесторонне отражён в модели, только если эта модель подразумевает такую среду возникновения сознания, которая содержит области каузальной неопределённости, и сознание оказывается тем более развитым, чем больше такие области ограничивают каузально независимые гиперсетевые процессы. Такой подход идейно противоположен теории интегрированной информации Тонини, которая утверждает, что «уровень» сознания определяется степенью интегрированности информации в нервной системе. Однако, до определённой степени несистемный подход обнаруживает когерентность с теорией интегрированной информации, так как подразумевается, что число каузальных неопределенностей и разрывов возрастает с общей информационной сложностью нервной системы. Поэтому до определённого предела рост индекса интегральной информации соответствует росту сложности «несистемы». В то же время, данный подход принципиально отличен, так как иначе трактует феномен сознания и метод его количественной оценки.

\section{О связи различных свойств сознания}

Перечислим рассмотренные выше свойства сознания, и укажем, как именно они связаны друг с другом. Это следующие свойства. 
1. Свойство передавать каузальность без передачи информации

2. Свойство занимать положение надсистемы по отношению к предшествующим более ранним системам или системам более низкого уровня

Так как передача каузальности без передачи информации возможна только в случае наличия онтологического (информационного) барьера или разрыва, то из первого свойства также следует свойство (3):

3. Свойство каузально заполнять онтологический (или информационный) разрыв или преодолевать онтологический барьер

С другой стороны, в силу динамического свойства (2), можно предположить, что сознание также обладает свойством (4):

4. Свойство формировать динамическое ядро некоей каузальной среды

Наконец, объединяя свойства (3) и (4), мы можем гипотетически предположить, что сознание также обладает свойством (5):

5. Свойство заполнять онтологический (информационный) разрыв между динамическим ядром каузальной среды и другими каузальными средами

Логика перехода от свойств (1) и (2) к свойству (5) требует более детального рассмотрения. Тем не менее, важно отметить, что в пределах свойств (1) и (2) уже намечается, но ещё не раскрывается тема отказа от монистических представлений о сознании. Начиная со свойства (3) тема обращения к плюралистической модели становится уже более строго определённой.

С целью сохранения научного подхода к проблеме, и негативной коннотации в научной среде ряда философских понятий, целесообразно вместо понятий плюрализм или мультисубстанциональность использовать понятие "несистема" или другой синоним. В этом случае, если система это «комплекс взаимодействующих компонентов» (Л. фон Берталанфи) [17] или «множество взаимосвязанных элементов, обособленное от среды и взаимодействующее с ней, как целое (Ф.И. Перегудов, Ф.П. Тарасенко) [18], то под несистемной подразумевается комплекс невзаимодействующих друг с другом элементов. А точнее, комплекс элементов, не взаимодействующих друг с другом в классическом понимании этого термина. Элементы такого комплекса не обмениваются массой, энергией или информацией, но в то же время в несистемах при определённых условиях теоретически может наблюдаться случайное взаимодействие, а также синхронизация процессов и другие формы связности. Однако, для описания этих форм пока не существует ни необходимого понятийного аппарата, ни соответствующей теории.

\section{ЛИТЕРАТУРА}

1. В.В. Васильев Сознание и вещи: Очерк феноменалистической онтологии. М.: Книжный дом «ЛИБРОКОМ», 2014. — c.135.

2. Д.И. Дубровский Субъективная реальность и мозг: два вопроса, требующих теоретического решения // Философия, социология, политология, 2010 г.

3. С. Сеунг. Коннектом. Как мозг делает нас тем, что мы есть / «Лаборатория знаний», 2016. 440с.

4. Safronov A.V. (2021). Topologia causal e causas não materiais. Laplage Em Revista, 7(2), p.575-585. https://doi.org/10.24115/\$2446-6220202172867p.575-585

5. Чалмерс Д. Сознающий ум: В поисках фундаментальной теории. М.: УРСС: Книжный дом «ЛИБРИКОМ», 2013.

6. Дубровский Д.И. Зачем субъективная реальность, или «почему информационные процессы не идут в темноте?» (Ответ Д. Чалмерсу)// Философские науки, 2011, 7-1.

7. Нагель Т. Каково быть летучей мышью? / Пер. с англ. М.А. Эскиной. Самара, 2003.

8. Jackson, Frank. Epiphenomenal Qualia // Philosophical Quarterly. — 1982. Vol 32. № 127. P. 127-136.

9. Tononi G. Integrated information theory of consciousness. Some ontological considerations. The Blackwell companion to consciousness. Eds. Schneider S., Velmans M. Chichester: John Wiley \& Sons, 2017. 621-633

10. К.В. Анохин. Когнитом: в поисках фундаментальной нейронаучной теории сознаний // Журнал высшей нервной деятельности им. И.П. Павлова, 2021, Т. 71, № 1, стр. 39-71

11. А.В. Сафронов Каузальный дуализм: размышления об онтологии и природе сознания / М.: Эксмо, 2021, 224с.

12. Newman, John D; Harris James C (Jan 2009). «The scientific contributions of Paul D. MacLean (1913-2007)». J. Nerv. Ment. Dis. United States. 197 (1): 3-5. doi:10.1097/NMD.0b013e31818ec5d9

13. Альтшуллер Г.С., Творчество как точная наука, М., «Советское радио», 1979 г., с. 126.

14. Dennett D.C. The message is: There is no medium. Philosophy and Phenomenological Research, 1993, 53:919-31.

15. Crick F. The astonishing hypothesis. The scientific search for the soul. New York: Scribner. 1994. 336 p.

16. Берталанфи Л. фон. История и статус общей теории систем // Системные исследования. - М.: Наука, 1973.

17. Перегудов Ф.И., Тарасенко Ф.П. Введение в системный анализ. - М.: Высшая школа, 1989. 